\title{
EFEKTIFITAS DAYA BERKECAMBAH BENIH PADI PANDANWANGI DENGAN MENGGUNAKAN METODE KERTAS
}

\author{
Oleh : \\ Nurdi Ibnu Wibowo \\ Widyaiswara Madya PPPPTK Pertanian
}

\begin{abstract}
Abstrak
Indonesia memiliki beragam jenis varietas padi, diantaranya ialah padi Pandanwangi. Padi Pandanwangi merupakan padi yang telah dikenal sebagai salah satu komoditi padi dan salah satu produk beras yang paling diunggulkan di Cianjur, Jawa Barat. Penelitian ini bertujuan untuk menguji efektifitas daya berkecambah benih padi Pandanwangi dengan menggunakan metode kertas. Dengan penelitian ini diharapkan mampu meningkatkan kemungkinan benih untuk berkecambah dengan optimal. Rancangan percobaan yang digunakan dalam penelitian ini ialah Rancangan Acak Lengkap (RAL) Faktorial. Dimana yang menjadi faktor $\mathrm{A}$ adalah metode pengujian daya kecambah benih padi Pandanwangi dengan menggunakan tiga level perlakuan (Top of Paper (Pada Kertas/PK), Between Paper (Antar Kertas/AK), dan Plated Paper (Antar Kertas Kipas/AK)), sedangkan untuk faktor B adalah jenis kertas dengan tiga level perlakuan, yaitu: kertas stensil, kertas merang, dan kertas buram, dengan empat kali ulangan. Berdasarkan penelitian yang telah dilaksanakan, dapat disimpulkan bahwa: Faktor A (metode) berpengaruh terhadap parameter presentase kecambah normal, panjang rata-rata radikula, dan panjang rata-rata plumula. Metode between paper dan metode pleated paper merupakan metode yang memberikan pengaruh paling baik terhadap ketiga parameter tersebut. Faktor B (jenis kertas) berpengaruh terhadap parameter panjang rata-rata radikula dan panjang rata-rata plumula. Kertas stensil merupakan jenis kertas yang memberikan pengaruh paling baik terhadap kedua parameter tersebut. Interaksi perlakuan (metode pengecambahan yang diinteraksikan dengan jenis kertas) berpengaruh terhadap parameter panjang rata-rata plumula. Kombinasi perlakuan pleated paper dan kertas stensil merupakan kombinasi perlakuan yang memberikan pengaruh paling baik.
\end{abstract}

Kata kunci: Pandanwangi, benih, Radikula, Plumula, Kertas.

\begin{abstract}
Indonesia has various types of rice varieties, including Pandanwangi rice. Pandanwangi Rice is rice that has been known as one of the rice commodities and one of the most superior rice products in Cianjur, West Java. This study aims to test the effectiveness of Pandanwangi rice seed germination by using the paper method. With this research it is expected to be able to increase the likelihood of seeds to germinate optimally. The experimental design used in this study was a Factorial Complete Randomized Design (CRD). Where the factor $A$ is the Pandanwangi rice seed germination test method by using three treatment levels (Top of Paper (On Paper / PK), Between Paper (AK) and Plated Paper (AK) (Fan Paper / AK)), while for factor $B$ is a type of paper with three levels of treatment, namely: stencil paper, straw paper, and opaque paper, with four replications. Based on the research that has been carried out, it can be concluded that: Factor A (method) influences the percentage of normal sprout percentage, average length of radicles, and average length of plumules. The method between the paper and the pleated paper method is the method that gives the best effect on these three parameters. Factor B (paper type) affects the parameters of the average length of the radicles and the average length of the plumula. Stencil paper is the type of paper that gives the best effect on
\end{abstract}

EFEKTIFITAS DAYA BERKECAMBAH BENIH

PADI PANDANWANGI DENGAN

IBNU NURDI WIBOWO

MENGGUNAKAN METODE KERTAS 
these two parameters. Treatment interactions (germination methods interacted with paper types) affect the average length parameters of the plumula. The combination of pleated paper and stencil paper is the combination of treatments that gives the best effect.

Keywords: Pandanwangi, Seeds, Radicula, Plumula, Paper. 


\section{PENDAHULUAN}

Indonesia memiliki beragam jenis varietas padi, diantaranya ialah padi Pandanwangi. Padi Pandanwangi merupakan padi yang telah dikenal sebagai salah satu komoditi padi dan salah satu produk beras yang paling diunggulkan di Cianjur, Jawa Barat, bahkan merupakan produk kebanggaan dalam skala Nasional. Karena, padi Pandanwangi hanya bisa ditanam di daerah Cianjur saja, bahkan di daerahnya sendiri padi Pandanwangi hanya mampu ditanami di beberapa kecamatan saja, tidak semua daerah dapat ditanami padi Pandanwangi, menurut Nizarli, dkk (2012) sentra penanaman yang paling terkenal yaitu dari daerah Kecamatan Warungkondang, Cugenang, Cibeber, Cianjur, Cilaku dan Kecamatan Campaka. Tanaman padi Pandanwangi menghendaki persyaratan iklim, ketinggian tempat, dan jenis tanah yang sangat lokalitas, sehingga bagi daerahdaerah lain pertumbuhan dan hasilnya kurang baik. Padi Pandanwangi apabila ditanam di luar daerah tersebut rasanya berbeda dan aromanya tidak muncul. Potensi beras Pandanwangi sangat besar dengan kualitas dan karakteristik yang belum tentu dimiliki oleh beras unggulan lainnya.

Di samping semakin pesatnya laju pertumbuhan penduduk Indonesia banyak cara yang telah ditempuh untuk mengimbangi pertumbuhan penduduk dengan hasil produksi pangan, salah satunya ialah usaha untuk menghasilkan benih bermutu demi terjaminnya pertumbuhan tanaman pangan sekaligus menjaga kualitas dan kuantitas warisan bangsa seperti komoditi padi Pandanwangi. Upaya untuk meningkatkan mutu tanaman padi terus digalakkan dari generasi ke generasi lainnya, berbagai teknologi pertanian serta temuan-temuan baru terus berkembang seiring berjalannya waktu. Upaya untuk menghasilkan benih unggul juga tak luput dari perhatian pelaku pengawasan mutu benih. Benih unggul merupakan benih yang telah lolos melalui uji coba di laboratorium yang sesuai dengan persyaratan dan dilakukan oleh tenaga ahli dan hasil akhirnya memperlihatkan kelebihan-kelebihan tersendiri jika dibandingkan dengan varietas lain.

Demi mendapatkan hasil tersebut, informasi yang benar mengenai mutu benih sangat diperlukan oleh produsen, pedagang, dan pengguna benih. Agar didapatkan informasi yang benar, pelaksanaan uji mutu benih, conohnya uji daya kecambah benih, harus berpatokan pada reproduksibilitas yang tinggi.

Benih dikatakan berkualitas/ bermutu adalah benih yang sudah diakui sebagai benih berkualitas/bermutu dari suatu tanaman bervarietas unggul. Benih berkualitas/bermutu memiliki daya tumbuh minimal 95\% dengan ketentuan sebagai berikut:

a) Berkemampuan atau dapat melangsungkan hidupnya menjadi tanaman unggul (berkecambah, tumbuh normal, dan menghasilkan produk yang baik),

b) Mempunyai tingkat kemurnian (Tueness seeds) tinggi, seperti bersih dari kotoran, tidak tercampur dengan benih tanaman lain, benih varietas lain, dan bebas dari hama dan penyakit (Ance dalam Nuno, 2017).

Pengujian daya kecambah dapat memperkirakan kualitas atau mutu benih tersebut. Daya kecambah dapat diartikan sebagai kemampuan suatu benih untuk mekar atau berkembangnya bagian-bagian vital dari embrio untuk tumbuh secara normal pada lingkungan yang sesuai. Proses perkecambahan yang normal akan melalui suatu rangkaian atribut perkecambahannya, yaitu calon akar (radikula) dan calon batang dan daun (plumula) dan keduanya mampu tumbuh normal dengan waktu yang tepat sesuai dengan International Seed Testing Association (ISTA) RULES (Humadini, 2011)..

Alimoeso (2016) menyatakan bahwa banyak metode pengujian daya kecambah atau daya tumbuh, salah satu metode yang sering digunakan ialah metode yang dilakukan adalah Top of Paper (Pada Kertas/PK), Between Paper (Antar Kertas/AK), dan Plated Paper (Antar Kertas Kipas). Pengujian hendaknya 
dilakukan pada benih murni agar hasilnya lebih menjamin.

Metode pada kertas ini sejatinya menggunakan berbagai macam kertas untuk dijadikan sebagai media tumbuh kecambah, kertas yang biasa digunakan dalam uji coba biasanya menggunakan kertas stensil, kertas merang dan kertas buram.

Berdasarkan uraian di atas maka dilakukan penelitian tentang uji efektifitas daya berkecambah benih padi Pandanwangi dengan menggunakan metode kertas. Dengan penelitian ini diharapkan mampu meningkatkan kemungkinan benih untuk berkecambah dengan optimal.

\section{METODE PENELITIAN}

\section{Waktu dan Tempat}

Penelitian dilaksanakan mulai dari bulan Januari 2019 sampai dengan bulan Maret 2019 bertempat di Pusat Pengembangan dan Pemberdayaan Pendidikan dan Tenaga Kependidikan Pertanian (P4TK Pertanian) atau VEDCA (Vocational Education Development Center for Agriculture) Cianjur, Jawa Barat.

\section{Alat dan Bahan}

Alat yang digunakan ialah; pinset, handcounter, baki, alat tulis kantor, label, tissu, $\mathrm{pH}$ meter, germinator dan kamera ponsel. Bahan yang digunakan ialah benih padi Pandanwangi, air $\mathrm{pH}$ netral, dan alkohol $70 \%$

Tabel 1. Kombinasi Perlakuan.

\begin{tabular}{lll}
\hline$(\mathrm{A} 1 \mathrm{~B} 1) \mathrm{a}$ & $(\mathrm{A} 2 \mathrm{~B} 1) \mathrm{a}$ & $(\mathrm{A} 3 \mathrm{~B} 1) \mathrm{a}$ \\
$(\mathrm{A} 1 \mathrm{~B} 1) \mathrm{b}$ & $(\mathrm{A} 2 \mathrm{~B} 1) \mathrm{b}$ & $(\mathrm{A} 3 \mathrm{~B} 1) \mathrm{b}$ \\
$(\mathrm{A} 1 \mathrm{~B} 1) \mathrm{c}$ & $(\mathrm{A} 2 \mathrm{~B} 1) \mathrm{c}$ & $(\mathrm{A} 3 \mathrm{~B} 1) \mathrm{c}$ \\
$(\mathrm{A} 1 \mathrm{~B} 1) \mathrm{d}$ & $(\mathrm{A} 2 \mathrm{~B} 1) \mathrm{d}$ & $(\mathrm{A} 3 \mathrm{~B} 1) \mathrm{d}$ \\
$(\mathrm{A} 1 \mathrm{~B} 2) \mathrm{a}$ & $(\mathrm{A} 2 \mathrm{~B} 2) \mathrm{a}$ & $(\mathrm{A} 3 \mathrm{~B} 2) \mathrm{a}$ \\
$(\mathrm{A} 1 \mathrm{~B} 2) \mathrm{b}$ & $(\mathrm{A} 2 \mathrm{~B} 2) \mathrm{b}$ & $(\mathrm{A} 3 \mathrm{~B} 2) \mathrm{b}$ \\
$(\mathrm{A} 1 \mathrm{~B} 2) \mathrm{c}$ & $(\mathrm{A} 2 \mathrm{~B} 2) \mathrm{c}$ & $(\mathrm{A} 3 \mathrm{~B} 2) \mathrm{c}$ \\
$(\mathrm{A} 1 \mathrm{~B} 2) \mathrm{d}$ & $(\mathrm{A} 2 \mathrm{~B} 2) \mathrm{d}$ & $(\mathrm{A} 3 \mathrm{~B} 2) \mathrm{d}$ \\
$(\mathrm{A} 1 \mathrm{~B} 3) \mathrm{a}$ & $(\mathrm{A} 2 \mathrm{~B} 3) \mathrm{a}$ & $(\mathrm{A} 3 \mathrm{~B} 3) \mathrm{a}$ \\
$(\mathrm{A} 1 \mathrm{~B} 3) \mathrm{b}$ & $(\mathrm{A} 2 \mathrm{~B} 3) \mathrm{b}$ & $(\mathrm{A} 3 \mathrm{~B} 3) \mathrm{b}$ \\
$(\mathrm{A} 1 \mathrm{~B} 3) \mathrm{c}$ & $(\mathrm{A} 2 \mathrm{~B} 3) \mathrm{c}$ & $(\mathrm{A} 3 \mathrm{~B} 3) \mathrm{c}$ \\
$(\mathrm{A} 1 \mathrm{~B} 3) \mathrm{d}$ & $(\mathrm{A} 2 \mathrm{~B} 3) \mathrm{d}$ & $(\mathrm{A} 3 \mathrm{~B} 3) \mathrm{d}$ \\
\hline
\end{tabular}

1) Alat yang digunakan untuk metode Top Of Paper ialah; 12 buah baki, wrapping plastic, pinset, kertas stensil, kertas buram, dan kertas merang.

2) Alat yang digunakan untuk metode Between Paper ialah; 12 lembar plastik mika, kertas merang, kertas stensil, dan kertas buram, dan pinset.

3) Alat yang digunakan untuk metode Plated Paper ialah; 12 buah baki, wrapping plastic, pinset, kertas stensil, kertas buram, dan kertas merang.

\section{Metode dan Rancangan Penelitian}

Rancangan percobaan yang digunakan dalam penelitian ini ialah Rancangan Acak Lengkap (RAL) Faktorial. Dimana yang menjadi faktor A adalah metode pengujian daya kecambah benih padi Pandanwangi dengan menggunakan tiga level perlakuan (Top of Paper (Pada Kertas/PK), Between Paper (Antar Kertas/AK), dan Plated Paper (Antar Kertas Kipas/AK)), sedangkan untuk faktor $\mathrm{B}$ adalah jenis kertas dengan tiga level perlakuan, yaitu: kertas stensil, kertas merang, dan kertas buram, dengan empat kali ulangan. Perlakuan tersebut yaitu;
A. Metode
A1: Kertas Di gulung
A2: Di Atas Kertas
A3: Di Antara Kertas
B. Jenis Kertas
B1: Kertas Stensil
B2: Kertas Merang
B3: Kertas Buram 
Setiap perlakuan dilakukan empat kali ulangan dengan menggunakan 100 benih, sehingga didapat 36 unit percobaan dengan total 3600 benih.

\section{Metode Kerja}

1. Pemilihan benih murni sebanyak 3.600, benih murni dilihat seraca fisik. Benih murni memiliki fisik yang utuh, tidak cacat, tidak terkena hama dan/atau penyakit, dan sesuai dengan ukuran yang semestinya.

2. Uji $\mathrm{pH}$ air dan $\mathrm{pH}$ kertas, $\mathrm{pH}$ harus memiliki kadar yang netral.

3. Membersihkan plastik mika dan baki dengan menggunkan alcohol yang disemprotkan dan dilap dengan menggunakan tissu.

\section{Metode kerja Top Of Paper}

Siapkan 12 buah baki. Bagi baki tersebut untuk 3 jenis perlakuan (untuk bahan kertas buram, stensil, dan merang) masing-masing perlakuan dilakukan 4 kali ulangan, setiap ulangan diuji dengan memasukan 100 benih untuk menguji daya kecambah. Setiap perlakuan menggunakan 5 lembar kertas macakmacak, benih ditabur pada lapisan teratas, tutup rapat dengan menggunakan plastik wrapping, beri label, dan masukan ke dalam germinator.

\section{Metode Kerja Between Paper}

Siapkan 12 plastik mika. Bagi mika tersebut untuk 3 jenis perlakuan (untuk bahan kertas buram, stensil, dan merang) masing-masing perlakuan dilakukan 4 kali ulangan, setiap ulangan diuji dengan memasukan 100 benih untuk menguji daya kecambah. Setiap perlakuan menggunakan 5 lembar kertas macakmacak, benih ditabur pada lapisan kertas ke-3 dan ditutup dengan 2 lapis kertas macak-macak, gulung, ikat dengan karet, beri label, dan masukan ke dalam germinator.

\section{Metode kerja Plated Paper}

Siapkan 12 buah baki. Bagi baki tersebut untuk 3 jenis perlakuan (untuk bahan kertas buram, stensil, dan merang) masing-masing perlakuan dilakukan 4 kali ulangan, setiap ulangan diuji dengan memasukan 100 benih untuk menguji daya kecambah. Setiap perlakuan menggunakan 5 lembar kertas yang dilipat menyerupai bentuk akordion/kipas dan kertas tersebut macak-macak, benih ditabur pada lapisan teratas, tutup rapat dengan menggunakan plastik wrapping, beri label, dan masukan ke dalam germinator.

\section{Teknik Pengumpulan Data}

Teknik pengumpulan data yaitu dengan cara memisahkan kecambah normal, mengukur panjang radikula, dan mengukur panjang plumula setelah satu minggu penaburan benih. Adapun kriteria kecambah normal adalah; kecambah yang memiliki semua struktur kecambah penting yang berkembang dengan baik, seperti akar semi primer dan semi skunder terlihat jelas.

Setelah kecambah normal berhasil diidentifikasi, selanjutnya kecambah normal dihitung dengan menggunakan rumus (Alimoeso, 2016);

Kecambah normal $=$

Kecambah yang Tumbuh Normal

Benih yang Ditaburkan $x 100 \%$

Adapula teknik pengumpulan data untuk mengukur panjang radikula dengan cara mengukur akar primer dari pangkal sampai ujung akar terpanjang dengan satuan sentimeter. Pengukuran dilakukan mulai sejak akar primer tumbuh sampai dengan hari 7 HST. Sedangkan plumula dihitung dari pangkal plumula hingga ujung plumula (Kartika dkk, 2013). Radikula dan plumula diambil secara acak 10 kecambah/ perlakuan, lalu panjang radikula tersebut dijumlahkan dan dirataratakan, begitu juga dengan plumula.

\section{Teknik Analisis Data}

Data yang telah diperoleh, lalu diolah dan dianalisis dengan menggunakan aplikasi komputer yaitu Minitab 15 dengan tujuan untuk mengetahui teknik terbaik untuk daya berkecambah benih Pandanwangi menggunakan teknik pengujian dengan menggunakan metode Top of Paper (Pada 
Kertas/PK), Between Paper (Antar Kertas/AK), dan Plated Paper (Antar Kertas Kipas /AK) dengan jenis kertas stensil, kertas buram, dan kertas merang, serta interaksi metode pengujian dengan jenis kertas terhadap jumlah kecambah normal, kecambah abnormal, dan benih mati.

\section{Pengujian Hipotesis}

Data yang diperoleh selanjutnya dianalisis dengan menggunakan Analisa Sidik Ragam atau ANOVA (Analisysis of Variance) uji nilai $\mathrm{F}$ kemudian untuk faktor perlakuan yang berpengaruh akan dilakukan uji lanjut Tuckey pada taraf $\alpha$ $5 \%$.

\section{HASIL DAN PEMBAHASAN}

\section{Perhitungan Kecambah Normal Padi Pandanwangi Cianjur}

Kecambah normal adalah kecambah yang menunjukkan kemampuan untuk berkembang menjadi tanaman normal jika ditanam dalam kondisi optimum (Widajati, dkk 2015). Menurut ISTA (International Seed Testing Association), penentuan kecambah (bibit) yang normal ini dilakukan selama batas periode pengujian perkecambahan (germination period) yang berbeda-beda untuk masing-masing jenis biji (species). Untuk bibit (kecambah) padi (oryza sativa) umur 7-9 hari.

Tabel 1. Hasil perhitungan kecambah normal benih padi Pandanwangi Cianjur pada setiap masingmasing faktor (7 hst)

\begin{tabular}{lc}
\hline \multicolumn{1}{c}{ Perlakuan } & Rata-rata persentase kecamb \\
\hline Faktor A (metode) & $84.25 \mathrm{~b}$ \\
A1= Top of paper & $91.00 \mathrm{a}$ \\
A2= Between paper & $88.50 \mathrm{ab}$ \\
A3= Pleated paper & \\
& \\
Faktor B (jenis kertas) & $88,08 \mathrm{a}$ \\
B1= Stensil & $88,00 \mathrm{a}$ \\
B2= Merang & $87,66 \mathrm{a}$ \\
B3= Buram &
\end{tabular}

Keterangan: Angka rata-rata yang diikuti huruf yang berbeda pada satu kolom menunjukan berbeda nyata hasil uji Tukey pada taraf $5 \%$.

Hasil perhitungan dari rata-rata kecambah normal dari masing-masing metode perlakuan yang diberikan dapat dilihat bahwa hasil tertinggi dalam perhitungan yang didapat ialah metode A2 yaitu between paper dengan hasil 91,00\% kecambah normal tumbuh. Sementara itu, metode pengecambahan benih dengan metode A3 yaitu pleated paper tidak berbeda nyata dengan A2 yaitu between paper dengan hasil 88,50\% kecambah normal tumbuh, dan yang berbeda nyata dengan A2, yaitu metode A1 yaitu top of paper dengan presentase kecambah normal tumbuh sebesar $84,25 \%$.

Sementara itu, hasil perhitungan dari rata-rata kecambah normal dari masing-masing metode perlakuan yang diberikan dapat dilihat bahwa baik untuk B1 (kertas stensil) dengan presentase $88,08 \%$, B2 (Kertas merang) dengan presentase 88,08\%, dan B3 (Kertas Buram) dengan presentase 87,66\% menunjukan tidak ada perbedaan nyata antara ketiga jenis kertas tersebut. Hal itu dapat dilihat pada simbol 'a' yang tertera di belakang angka yang memperlihatkan keseragaman antara ketiga jenis kertas berbeda tersebut.

Dalam hal ini dapat diidentifikasi bahwa metode between paper merupakan metode terbaik untuk mengecambahkan benih normal padi Pandanwangi, hal tersebut berbeda dengan teori menurut Hossain et, al, (2013) yang memaparkan bahwa metode UKD (Uji Kertas Digulung (between paper)) ialah metode yang digunakan untuk benih yang tidak peka cahaya untuk proses perkecambahannya. Benih yang memiliki ukuran besar seperti benih jagung, kedelai, kacang tanah, dll. Namun hal tersebut 
tidak selamanya seperti itu, banyak penelitian seperti yang telah dilakukan oleh Suwarno, dkk (2008) yang menggunakan metode between paper untuk mengecambahkan benih padi. Metode pengujian between paper dan metode pleated paper merupakan metode pengujian yang hampir sama. Perbedaannya adalah pada between paper digunakan plastik sebagai alas dan digulung bersama dengan media kertasnya, sedangkan pada metode pleated paper penggunaannya tanpa plastik dan hanya dilipat. Kedua metode uji perkecambahan (pleated paper dan between paper) merupakan metode uji yang baik karena memberikan kondisi optimum bagi perkecambahan benih (Rahmawati dan Syamsudin 2013).

Sedangkan untuk jenis kertas yang tidak memiliki pengaruh terhadap kecambah normal dikarenakan setiap kertas memiliki potensi yang sama untuk mengecambahkan kecambah normal. Hal ini didukung oleh teori menurut Suwarno, dkk (2008) menyatakan bahwa sifat fisik kertas stensil meskipun tidak persis sama dengan kertas merang, namun sangat optimum untuk perkecambahan benih, karena memiliki daya serap air yang relatif tinggi (24.40g/unit media), seragam dalam daya serap dan mempertahankan air Tabel 2. Hasil perhitungan panjang radikula kecambah padi Pandanwangi Cianjur pada setiap masingmasing faktor ( 7 hst)

\begin{tabular}{lc}
\hline \multicolumn{1}{c}{ Perlakuan } & Rata-rata panjang radikula $\mathbf{( c m )}$ \\
\hline Faktor A (metode) & \\
\hline A1= Top of paper & $7,50 \mathrm{bc}$ \\
A2= Between paper & $8,26 \mathrm{abc}$ \\
A3= Pleated paper & $8,41 \mathrm{ab}$ \\
& \\
Faktor B (jenis kertas) & \\
B1= Stensil & $8,72 \mathrm{a}$ \\
B2= Merang & $7,81 \mathrm{bc}$ \\
B3= Buram & $7,64 \mathrm{bc}$ \\
\hline
\end{tabular}

Keterangan: Angka rata-rata yang diikuti huruf yang berbeda pada satu kolom menunjukkan berbeda nyata hasil uji Tuckey pada taraf 5\%.

Berdasarkan hasil uji beda di atas, dapat dilihat bahwa pada faktor A (metode) pada metode A3 yang memiliki rata-rata panjang radikula sebesar $8,41 \mathrm{~cm}$ tidak berbeda nyata dengan metode A2 yang memiliki rata-rata panjang radikula $8,26 \mathrm{~cm}$, dan juga tidak berbeda nyata dengan metode A1 yang memiliki panjang rata-rata radikula $7,50 \mathrm{~cm}$. (koefesien keseragaman $<5 \%$ serta mampu mempertahankan air selama pengujian viabilitas benih (7 hari). Hasil pengujian viabilitas benih juga menunjukan bahwa kertas stensil memiliki tingkat kesamaan yang paling tinggi berdasarkan tolok ukur daya berkecambah benih dan 91,7\% berdasarkan tolok ukur bobot kering kecambah normal. Suwarno, dkk (2008) juga menambahkan bahwa kertas stensil dan kertas buram/CD merupakan kertas yang menunjukkan kemampuan menyerap air, mempertahankan air, dan kecepatan penyerapan air yang baik, dan sangat potensial untuk dijadikan sebagai penggganti substrat alternatif pengganti kertas merang.

\section{Perhitungan Panjang Radikula}

Radikula adalah poros embrio yang tumbuh ke bawah dan akan menjadi akar primer atau radikula merupakan bakal calon akar yang tumbuh selama masa perkecambahan. Fungsinya adalah sebagai bagian tanaman yang akan berkembang menjadi akar tanaman yang akan menyokong dan menyuplai bahan - bahan makanan untuk diproses pada bagian tanaman lainnya (Julian, 2015) dengan kertas merang, yaitu 100\% 
Rahmawati (2013) bahwa metode pengujian between paper dan metode pleated paper merupakan metode pengujian yang hampir sama. Kedua metode uji perkecambahan (pleated paper dan between paper) merupakan metode uji yang baik karena memberikan kondisi optimum bagi perkecambahan benih. Maka dari itu, metode ini memberikan hasil terbaik bagi absorbsi kepada benih sehingga benih mampu menyerap air dengan optimal dan radikula mampu tumbuh dengan baik.

Selanjutnya, dilihat dari perlakuan jenis kertas yang diberikan dapat dilihat bahwa kertas stensil merupakan kertas yang paling ideal untuk pertumbuhan kecambah normal bagi benih padi Pandanwangi dengan panjang radikula $(8,72 \mathrm{~cm})$ dalam 7 hst. Meskipun menurut Suwarno, dkk (2008) daya absorbsi dan kemampuan mempertahankan air masingmasing jenis kertas (merang, buram, HVS, stensil, filter, dan samson) menunjukan bahwa kertas merang adalah substrat yang memiliki kemampuan terbesar dalam penyerapan air. Namun pada dasarnya tidak ada ketentuan yang khusus yang menentukan berapa konsentrasi air yang harus diberikan pada setiap lembaran kertas yang digunakan dalam uji kecambah benih, hal ini dikhawatirkan bahwa kertas merang yang memiliki kemampuan mempertahankan air yang tinggi malah akan menjadikan benih tumbuh abnormal hingga benih busuk sehingga benih tidak mampu untuk berkecambah yang diakibatkan oleh kelebihan air yang diberikan pada saat waktu pengujian. Hal ini diperkuat oleh Fitriani (2015) yang menyatakan bahwa pada benih yang mati tidak ditandai dengan tidak adanya perkembangan dan pertumbuhan radikula. Benih ini mati berhubungan dengan tingginya kadar air yang menyebabkan struktur membran mitokondria tidak teratur sehingga permeabilitas membran meningkat. Banyak metabolit antara lain gula, asam amino dan lemak yang bocor keluar sel disebabkan peningkatan permeabilitas membran. Dengan demikian substrat untuk respirasi berkurang sehingga energi yang dihasilkan untuk berkecambah berkurang. Berkurang atau tidak masuknya air ke dalam biji, maka tidak atau kurang terjadi rehydration di dalam biji, sehingga menyebabkan tidak terjadi atau kurang sempurnanya proses perkecambahan.

\section{Perhitungan Panjang Plumula}

Radikula adalah bakal calon akar yang tumbuh ke bawah selama masa perkecambahan. Fungsi radikula adalah calon akar yang akan berkembang menjadi akar tanaman sebagai penyokong dan penyuplai bahan-bahan makanan untuk diproses pada bagian tanaman yang lainnya (Julian, 2015).

Pertumbuhan plumula yang sempurna yaitu yang memiliki daun berwarna hijau dan tumbuh dengan baik di dalam atau muncul dari koleoptil atau pertumbuhan epikotil yang sempurna dengan kuncup yang normal.

Tabel 3. Hasil perhitungan panjang plumula benih padi Pandanwangi Cianjur pada setiap masing-masing faktor (7 hst)

\begin{tabular}{lc}
\hline \multicolumn{1}{c}{ Kombinasi Perlakuan } & Rata-Rata Panjang Plumula (cm) \\
\hline A1B1 (Top of Paper + Kertas Stensil) & $2,81 \mathrm{~cd}$ \\
A1B2 (Top of Paper + Kertas Merang) & $1,48 \mathrm{e}$ \\
A1B3 (Top of Paper + Kertas Buram) & $2,43 \mathrm{de}$ \\
A2B1 (Between Paper + Kertas Stensil) & $4,75 \mathrm{~b}$ \\
A2B2 (Between Paper + Kertas Merang) & $6,04 \mathrm{a}$ \\
A2B3 (Between Paper + Kertas Buram) & $3,70 \mathrm{bc}$ \\
A3B1 (Pleated Paper + Kertas Stensil) & $6,45 \mathrm{a}$ \\
A3B2 (Pleated Paper + Kertas Merang) & $3,82 \mathrm{bc}$ \\
A3B3 (Pleated Paper + Kertas Buram) & $6,20 \mathrm{a}$ \\
\hline
\end{tabular}

Keterangan: Angka rata-rata yang diikuti huruf yang berbeda pada satu kolom menunjukkan berbeda nyata hasil uji Tukey pada taraf $5 \%$. 
Berdasarkan tabel 3, dapat dianalisis bahwa interaksi antara pleated paper dan kertas stensil (A3B1) merupakan hasil dengan panjang plumula paling tinggi dengan hasil $6,45 \mathrm{~cm}$, diikuti oleh metode pleated paper yang diinteraksikan dengan kertas buram dengan hasil 6,20 $\mathrm{cm}$, dan yang paling tinggi selanjutnya ialah metode between paper yang diinteraksikan dengan kertas merang (A2B2) dengan hasil 6,04 cm. Ketiga perlakuan tersebut berbeda nyata dengan perlakuan yang lainnya. Hasil paling rendah ialah interaksi antara top of paper dan kertas merang (A1B2) dengan hasil $1,48 \mathrm{~cm}$ yang hasilnya tidak berbeda nyata dengan perlakuan interaksi antara metode top of paper yang diinteraksikan dengan kertas buram (A1B3) dengan hasil 2,43 $\mathrm{cm}$.

Berdasarkan tabel di atas, interaksi pada metode pleated paper dan kertas stensil (A3B1) diikuti oleh metode pleated paper dan kertas buram (A3B3), dan yang terakhir moetode between paper dengan kertas merang (A2B2) merupakan interaksi paling tinggi untuk perkecambahan plumula, hal tersebut karena kertas stensil, kertas buram, dan kertas merang merupakan kertas yang paling ideal untuk mengecambahkan benih. Hal tersebut sesuai dengan penelitian yang dilakukan oleh Nugraha dkk (2003) dalam Chairani, dkk (2008) menyatakan bahwa kertas merang merupakan substrat pengujian daya berkecambah benih memberikan hasil yang nyata lebih tinggi.

Pada penelitian Suwarno (2008) diperoleh informasi bahwa secara keseluruhan, sifat fisik substrat kertas merang memang yang terbaik, karena memiliki daya absorpsi yang tinggi, seragam, mampu mempertahankan air dan kecepatan penyerapan air kapilernya tinggi, meskipun berfluktuasi. Kertas stensil dan kertas buram merupakan kertas yang berpotensi sebagai kertas yang dapat dijadikan alternatif pilihan selain kertas merang karena memiliki kemampuan menyerap air, mempertahankan air, dan kecepatan penyerapan air yang baik.
Secara keseluruhan, metode top of paper merupakan metode yang paling tidak direkomendasikan pada penelitian kali ini, karena dalam penelitian, metode top of paper merupakan metode yang tidak mampu mempertahankan air lebih lama di bandingkan dengan metode between paper dan pleated paper, sehingga, kertas menjadi cepat kering dan tidak bagus bagi imbibisi benih. Hal ini juga disampaikan oleh Meliala (2008) bahwa kekeringan dapat menyebabkan penguapan zat cair dari dalam benih, sehingga benih akan kehilangan daya imbibisi dan kemampuan untuk berkecambah. Protoplasma dari embrio dapat mati akibat kekeringan.

Kendati demikian, setiap perlakuan, masing-masing jenis kertas, dan masingmasing metode yang digunakan dalam penelitian akan memberikan hasil yang berbeda pula terhadap hasil pengujian daya berkecambah. Oleh karena itu pemilihan media tumbuh dan metode pengujian harus dipilih secara hati-hati.

\section{KESIMPULAN}

Berdasarkan penelitian yang telah dilaksanakan, dapat disimpulkan bahwa:

1. Faktor A (metode) berpengaruh terhadap parameter presentase kecambah normal, panjang rata-rata radikula, dan panjang rata-rata plumula. Metode between paper dan metode pleated paper merupakan metode yang memberikan pengaruh paling baik terhadap ketiga parameter tersebut.

2. Faktor B (jenis kertas) berpengaruh terhadap parameter panjang rata-rata radikula dan panjang rata-rata plumula. Kertas stensil merupakan jenis kertas yang memberikan pengaruh paling baik terhadap kedua parameter tersebut.

3. Interaksi perlakuan (metode pengecambahan yang diinteraksikan dengan jenis kertas) berpengaruh terhadap parameter panjang rata-rata plumula. Kombinasi perlakuan pleated paper dan kertas stensil merupakan kombinasi perlakuan yang memberikan pengaruh paling baik. 


\section{DAFTAR PUSTAKA}

Alimoeso, Sutarto 2006. Pedoman Laboratorium Pengujian Mutu Benih Tanaman Pangan dan Hortikultura. Jakarta: Departemen Pertanian.

Fitriani, Anggi. 2015. Uji Daya Perkecambahan Benib Dan Kunjungan Uptd Balai Benih Padi Dan Palawija Bojongsari. Universitas Muhammadiyah Purwokerto.

Humadini, Amrik (2011). Mengenal ISTA RULES, Dinas Pertanian Daerah Istimewa Yogyakarta

Julian, Tri Muhar. 2015, Pengaruh KNO3 dan Cahaya Terhadap Perkecambahan dan Pertumbuhan Kecambah Benih Padi (Oryza sativa L.) Varietas Ciherang, Fakultas Matematika dan Ilmu Pengetahuan Alam, Universitas Lampung

Kartika dkk. 2015. Pematahan Dormansi Benih Kelapa Sawit (Elaeis guineensis Jacq.) Menggunakan $\mathrm{KNO}_{3}$ Dan Skarifikasi. Enviagro, Jurnal Pertanian dan Lingkungan. Vol.8 No. 2, hal 48-55. Institut Pertanian Bogor. Bogor.

Meliala, Jessica. 2008. Pengarub Ruang, Media, Wadah Dan Periode Penyimpanan Terbadap Viabilitas Benih Manglid (Manglietia glauca Blume.). Skripsi. Institut Pertanian Bogor. Bogor.
Nizarli, dkk. 2012. Kontrak Berjangka Mengabdi Dengan Integritas. Bappebti/Mjl/136/XI/2012/Edisi Juli. Badan Pengawas Perdagangan Berjangka Komoditi. Jakarta Pusat.

Nuno, Lucio. 2017. Pengaruh Penundaan Waktu Prosesing Terbadap Mutu Benih Padi (Oryza sativa L.) Varietas Membramo. Universitas Udayana. Denpasar. Halaman 1.

Nugraha, Udin, dkk. 2003. Evaluasi Validitas Metode Pengujian Daya Berkecmabah Benib Padi. Balai Penelitian Tanaman Padi. Penelitian Pertanian Tanaman Pangan Vol. 22 No. 2.

Rahmawati dan Syamsudin. 2013. Penguiian Mutu Benih dengan Beberapa Metode. Seminar Nasional Serelia. Balai Penelitian Tanaman Serelia. Sulawesi Barat.

Suwarno, Chairani Faiza dan Indri Hapsari. 2008. Studi Alternatif Kertas untuke Penguijan Viabilitas Benib dengan Metode Uji UKDdp. Institut Pertanian Bogor. Bul. Agron. (36) (1) 84-91. Bogor.

Suwarno, Chairani Faiza dan Indri Hapsari. 2008. Studi Alternatif Kertas untuk Pengujian Viabilitas Benib dengan Metode Uji UKDdp. Institut Pertanian Bogor. Bul. Agron. (36) (1) 84-91. Bogor.

Widajati, Eny. 2013. Dasar Ilmu dan Teknologi Benih. IPB. IPB Press. Bogor 